\title{
LISBON / OPORTO RIVALRY IN THE 19TH AND 20TH CENTURIES \\ Maria Eugénia Mata
}

Uniwersidade Noun de Lisbo

\section{INTRODUCTION}

As pointed out in previous chapters, Lisbon and Oporto have boen, since the 18th century, the two main Portuguese urban centres, forming a class of their own, clearly different from any other Portuguese town. This has thrust the two communities into a rivalry which has left its imprint on almost every aspect of Portuguese social life.

This chapter examines the historical and geographical roots of the outstanding position of Lisbon and Oporto among Portuguese urban centres, and some aspects of their rivily during the 19th and 20th centuries.

In action 2 we shall examine the historical evolution that has made the two cities the main urban centres of the country. Section 3 includes the goographical background of Lisbon and Oporto, leuding plicos among Portuguese urban centres. We turn to their demographic growth during the 19th and 20th centuries in section 4. An analysis is presented in section 5 of the structure of the labour force in both cities, from the late 19th century on, as a general comparative survey of their conomic activitiss. Sections 6 and 7 deal with particular aspects of these economic activities, namely the roles of Lisbon and Oporto as transportation and financial centres. In setion 8 we take a political perspective, considering aguin only one purticular aspect - Lisbon and Oporto as places of birth of successful revolutions. Section 9 goes on to a cultural perspective, once more restricting the analysis to one particular aspect - this time university life. In section 10 are presented some general conclusions. 